\title{
Characterization of Vestibular Insult Associated with Sudden Sensorineural Hearing Loss
}

\author{
Alaa Eldin A. Abou-Setta, Ashraf S. Abou-Halawa, Tarek A. Elnahriry, and \\ Abdullah M. Hussiny*
}

Department of Otorhinolaryngology, Faculty of Medicine, Suez Canal University, Ismailia, Egypt

\begin{abstract}
Background: Sudden sensorineural hearing loss is considered a labyrinthine crisis, where the vestibular system is exposed to damage as well as the cochlea. Many trials have been made to prove the existence of such damage, in this study; we have utilized the VEMP and vHIT to characterize this vestibular insult and classify it into distinguishable patterns. Aim: To characterize the vestibular insult associated with sudden sensorineural hearing loss (SSNHL) using vestibular evoked myogenic potential (VEMP) and video head impulse test (VHIT). Patients and Methods: This crosssectional descriptive study was carried out on 31 patients with SSNHL presenting to Audiovestibular Medicine outpatient clinic in SCU hospital from April 2017 to Sep. 2018. Subjects with unilateral sudden diminution of hearing $>30 \mathrm{~dB}$ in three or more consecutive frequencies were included. A full audiological evaluation was done in addition to the VEMP both (cervical \& ocular) and vHIT. Results were analyzed and combined into four main different patterns by authors. Results: Among 31 subjects with SSNHL, 7 patients (22\%) had Type 1 (cochlear insult but no vestibular pattern), 14 patients, (45\%) had Type II (otolithic involvement: saccule and/or utricle), 6 patients (19\%) had type III (otolithic and semicircular canals involvement) and 4 patients (12\%) had type IV (complete vestibular loss). Conclusion: Vestibular insult in SSNHL was categorized into four types. Seventy eighty percent of patients had otolithic organ affection (Type I, II and III) while SCC insult was present in only $32 \%$ of patients (Type II, and III) with SSNHL.
\end{abstract}

Keywords: VEMP, vHIT, cochlear insult, otolithic involvement, semicircular canals

\section{Introduction}

Sudden sensorineural hearing loss (SSNHL) is defined as hearing loss of greater than 30 $\mathrm{dB}$ over 3 contiguous pure-tone frequencies on pure tone audiometry, occurring within 3 days' period ${ }^{(1)}$. It occurs as a result of different pathologies that can affect vestibular system as well as the cochlea. Unlike the cochlear pathology that can manifest with hearing loss or tinnitus(2), vestibular insult may not be clinically apparent. In spite of the prevalence of dizziness among patients with $\operatorname{SSNHL}^{(3,4)}$, literature have fewer evidence regarding the characterization of the vestibular insult associated with SSNHL compared to the auditory one. Vestibular function can be damaged by the same viral/vascular mechanisms that cause the clinically apparent SSNHL. Vestibular dysfunction, either clinically overt or subclinical, can result in both physical and psychological consequences. When experiencing challeng- 
ing situations to the vestibular system, patient may notice distressing balance problems that affect his daily life activities. The patient may have reduced postural control, and instability in standing, during ambulation, and during transitional activities such as moving from lying to sitting, or from sitting to standing $(3,4)$. Patients may also develop anxiety-depression symptoms, panic, agoraphobia, and cognitive defects, especially if elderly(5). So far, most available reports in literature have utilized solo tests for the assessment of vestibular dysfunction associated with SSNHL, like the VNG, searching coil, VEMP and rarely the VHIT. Comprehensive testing of the vestibular system can be done in most vestibular units: the otolith organs (sensors for linear acceleration) with Vestibular Evoked Myogenic Potential (VEMP) both cervical and ocular. The CVEMP is used to test saccule or inferior vestibular nerve while the oVEMP to test utricle or superior vestibular nerve. The semicircular canals (sensors for angular acceleration) can now be tested with the Video Head Impulse Test (vHIT) ${ }^{(6)}$. Vestibular system is composed of five end-organs (two otolith organs and three semicircular canals), each can be tested individually(7). Vestibular insult patterns can be mapped into different clinically distinct patterns depending on which of these organs are affected. Characterization of the insult in SSNHL patients helps us in adding the vestibular dimension to comprehension of SSNHL patho-mechanics, it could be utilized by future research, and can provide a guide to physician to tailor the vestibular rehabilitation to help the patient regain his balance ${ }^{(8)}$. The aim for this research is to use combined vestibular testing to characterize the vestibular insult in patients with SSNHL, by means of the VHIT, and the VEMP

\section{Patients and Methods}

The study was approved by the research Ethics committee of the Faculty of Medicine,
Suez Canal University. A consent was obtained from the patients before inclusion in the study. This descriptive cross-sectional study was conducted at the Audiovestibular Medicine outpatient clinic of the Suez Canal university hospital in Ismailia-Egypt during the period from April 2017 to Oct 2018. Patients diagnosed with SSNHL with puretone average of $\geq 30 \mathrm{~dB} \mathrm{HL}$ over at least 3 contiguous frequencies which developed within 72 hours were included in the study. Patients with any of the following criteria were excluded from the study, i) cervical muscle or vertebral pathology that may interfere with VEMP/VHIT. ii) middle ear pathology e.g. middle ear effusion and otosclerosis, that interfere with sound delivery to inner ear during VEMP. iii) age above 60 years to avoid the effect of vestibular system aging known as presbystasis.

\section{Study Methods}

Evaluation of the patients included full medical history emphasizing the otologic symptoms and vestibular symptoms, audiological and neurotological examination. SSNHL was confirmed with pure tone audiometry. Vestibular assessment was done using Neuro-Audio 2-channel VEMP, (Neurosoft Inc, Russia) to record cervical and ocular VEMP.

\section{(A) cVEMP}

After preparing the skin with a cleaning gel, three electrodes were mounted: the active electrode on the middle of the sterno-cleidomastoid (SCM) muscle; the inverting (reference) electrode on the upper sternum (suprasternal notch) and the ground electrode: on the forehead. The electrode impedance was kept below $5 \mathrm{~K}$ Ohms. Test was performed with the patient sitting upright and turning his chin over to the contra-lateral shoulder to tense the muscle during runs of acoustic stimulation. Patient was instructed to relax in between the runs to avoid fatigue. Tone burst $(500 \mathrm{~Hz})$ 
stimulation was presented monoaurally through air conduction, at intensity of $100 \mathrm{~dB}$ $\mathrm{nHL}$, via insert phones at stimulus rate of 5 $\mathrm{Hz}$. Time window for analysis was $50 \mathrm{~ms}$. At least 50 sweeps were recruited in each run and filtered through a bandpass filter of 30$1500 \mathrm{~Hz}$. Two trials of averaged signals were obtained to ensure reproducibility. The rectified VEMP amplitudes were recorded. The results were analyzed in comparison to the normative data established in our audiovestibular unit for CVEMP: P13 mean latency: 14.6 msec. (SD \pm 1.3 ), N23 mean latency $=23.7$ (SD \pm 0.9 . Inter-aural amplitude difference (IAD) of the two ears is measured as $\mathrm{P}_{13}-\mathrm{N} 23$ peak to peak amplitude (in $\mu \mathrm{v}$ ) difference between the right and left ears divided by the total amplitude of both ears i.e. $I A D=R t-L t R t+L t$. Abnormal latencies are those beyond $+2 S D$, while IAD is abnormal if $>32 \%$.

\section{(B) OVEMP}

After skin preparation, the positive electrode was placed on the orbital margin below the center of the eye with reference electrode on the cheek one-inch inferior to it, while the ground electrode was placed on the forehead. Test was performed with the patient sitting upright, relaxing his facial muscles, and looking upward without moving the head. Recording of contralateral excitatory muscle potential was obtained and graphed. Tone bursts $(500 \mathrm{~Hz})$ were presented monoaurally through air conduction at intensity of $100 \mathrm{dBnHL}$, via insert phones. Stimulus rate was: $5 \mathrm{~Hz}$. The time window for analysis was $50 \mathrm{~ms}$. At least 200 sweeps were with 1-1000 $\mathrm{Hz}$ filter were acquired. Two trials of averaged signals were obtained at each intensity to ensure reproducibility. The results were analyzed in comparison to the normative data established in our audiovestibular unit for OVEMP: N10 mean latency is $10.7 \mathrm{msec}$ (SD \pm $0.7)$ and $P 15$ mean latency is $16.5 \mathrm{msec}$ (SD \pm 1.1). IAD is measured as N10-p15 peak to a peak amplitude ((in $\mu v)$ between the two ears divided by the total amplitude of both ears: $I A D=R t-L t \quad / R t+L t$. Abnormal latencies are those beyond $+2 \mathrm{SD}$, while IAD is abnormal if $>34 \%$.

\section{C) Video head impulse test (VHIT)}

Patients wore the Difra Goggles (Difra Inc, Belgium) while sitting $1 \mathrm{~m}$ directly in front of a fixation target at eye level to avoid activation of the convergence system which may interfere with VOR and then they were instructed to keep their eyes open and fixed upon earth-mounted target. The system was first calibrated for the eye and head movements of the patient. Testing was then done with the examiner standing behind patient and rotating patient's head unpredictably (in direction and time). The direction of head impulse for lateral canal testing is to the left and right (yaw rotation), with head in $30^{\circ}$ flexion. For vertical canals testing, the direction of head impulse is up and down (pitch rotation) with the head $45^{\circ}$ from the median plane ${ }^{(9)}$. The head impulse amplitude range was $10^{\circ}-20^{\circ}$, duration range of 150-200 ms, peak acceleration range of $2000-6000 \% \mathrm{sec}^{2}$, and a peak velocity $200 \% \mathrm{sec}$. Each patient underwent at least of 10 head impulses in the plane of the tested SCC. The VHIT was considered abnormal if catch up saccades, either covert (within eye movement curve) or overt (after the eye movement curve) were present ${ }^{(10,11)}$ and/or the gain was $<0.8$. The latter was digitally calculated by comparing the area under curve (AUC) of eye movement to the AUC of head movement.

\section{Statistical Analysis}

Statistical analysis was performed using Statistical Package for the Social Sciences (SPSS) program version 20 for Windows10. $P$ value $<0.05$ was considered as statistically significant. 


\section{Results}

Thirty-one patients were included in this study (Table 1): 17 males (55\%) and 14 females (45\%). Age of the patients ranged from 15 to 60 years with mean age of $43 \pm 18$ years. All patients presented with unilateral SSNHL, 16 (52\%) in the right ear and $15(48 \%)$ in the left ear. Symptoms other than sudden diminution of hearing, included tinnitus in 26 patients (83\%), dizziness in 17 patients (55\%), and aural fullness in 10 patients (32\%). Nine patients $(29 \%)$ had profound $\mathrm{HL}, 8$ patients (26\%) had mild HL, 6 patients (20\%) had moderate $\mathrm{HL}, 5$ patients (17\%) had moderately severe $\mathrm{HL}$, and 3 patients (10\%) had severe HL.

\begin{tabular}{|c|c|}
\hline \multicolumn{2}{|c|}{$\begin{array}{l}\text { Table 1: Demographic data and hearing } \\
\text { testing results in the study group }\end{array}$} \\
\hline Variable & No (\%) \\
\hline No. of patients & 31 \\
\hline \multicolumn{2}{|l|}{ Gender } \\
\hline - Males & $17(55 \%)$ \\
\hline - Females & $14(45 \%)$ \\
\hline \multicolumn{2}{|l|}{$\operatorname{Age}(Y)$} \\
\hline - Range & $15-60$ \\
\hline$-\quad$ Mean $( \pm S D)$ & $43 \pm 18$ \\
\hline \multicolumn{2}{|l|}{ Ear affected } \\
\hline - Right & $16(52 \%)$ \\
\hline - Left & $15(48 \%)$ \\
\hline \multicolumn{2}{|l|}{ Ear symptoms } \\
\hline - SSNHL & $31(100 \%)$ \\
\hline - Tinnitus & $26(83 \%)$ \\
\hline - Dizziness & $17(55 \%)$ \\
\hline \multicolumn{2}{|l|}{ Degree of HL } \\
\hline - Mild & $8(26 \%)$ \\
\hline - Moderate & $6(20 \%)$ \\
\hline - Mod. Severe & $5(17 \%)$ \\
\hline - Sever e & $3(10 \%)$ \\
\hline - Profound & $9(29 \%)$ \\
\hline \multicolumn{2}{|l|}{ PTA } \\
\hline - High loss & $15(48 \%)$ \\
\hline - Flat curve & $8(26 \%)$ \\
\hline - Low loss & $4(13 \%)$ \\
\hline - Total loss & $4(13 \%)$ \\
\hline
\end{tabular}

\begin{tabular}{|c|c|}
\hline \multicolumn{2}{|c|}{$\begin{array}{l}\text { Table 2: Vestibular testing results of the } \\
\text { study group }\end{array}$} \\
\hline Variable & No $(\%)$ \\
\hline \multicolumn{2}{|l|}{ CVEMP } \\
\hline - Normal & $15(48 \%)$ \\
\hline - Low amplitude & $9(29 \%)$ \\
\hline - Prolonged latency & $4(14 \%)$ \\
\hline - Absent waves & $3(10 \%)$ \\
\hline \multicolumn{2}{|l|}{ oVEMP } \\
\hline - Normal & $11(35 \%)$ \\
\hline - Low amplitude & $7(23 \%)$ \\
\hline - Prolonged latency & $6(20 \%)$ \\
\hline - Absent waves & $7(23 \%)$ \\
\hline \multicolumn{2}{|l|}{ vHIT } \\
\hline - Normal & $21(68 \%)$ \\
\hline - LSSC affection & $9(29 \%)$ \\
\hline - SSCC affection & $9(29 \%)$ \\
\hline - PSCC affection & $5(16 \%)$ \\
\hline - Multiple canal affection & $9(29 \%)$ \\
\hline \multicolumn{2}{|l|}{ Vestibular insult type } \\
\hline - Type o & $7(23 \%)$ \\
\hline - Type I & $14(45 \%)$ \\
\hline - Type II & $6(20 \%)$ \\
\hline - $\quad$ Type III & $4(13 \%)$ \\
\hline \multicolumn{2}{|c|}{$\begin{array}{l}\text { CVEMP: cervical vestibular-evoked myogenic potential, } \\
\text { oVEMP: Ocular vestibular-evoked myogenic potential, } \\
\text { vHIT: video head impulse test, LSSC: lateral } \\
\text { semicircular canal, } \\
\text { SSCC: Superior semicircular canal, PSCC: posterior } \\
\text { semicircular canal }\end{array}$} \\
\hline
\end{tabular}

High frequency loss was present in 15 patients (48\%), flat curve in 8 patients (26\%), low-frequency loss in 4 patients (13\%), and total hearing loss in 4 patients (13\%). No correlation of the degree or configuration of Hearing Loss was present with patients' age or gender. Twenty-four patients (78\%) had vestibular insult (Table 2): 6 patients (19\%) had one vestibular end-organ affection (only the saccule or the utricle) and 18 (58\%) patients had multiple affection. No sole semicircular canal insult was found among the studied group. CVEMP results were as follows: 16 patients (51\%) had abnormal test results: 9 patients (29\%) had abnormal amplitude (IAD >32\%) , 4 patients (13\%) had prolonged waves latencies ( $\mathrm{P} 13>17.2 \mathrm{msec}$ ), and 3 patients (10\%) had complete absence 
of waves (no response) (Figures 1, 2). oVEMP test results were as follows: 20 patients (65\%) had abnormal test results: 7 had abnormal amplitude (IAD > 34\%), 6 patients (19\%) had prolonged waves latencies (N10 $>12.1 \mathrm{msec}$ ) (Figure 3), and 7 patients (23\%) had complete absence of waves (no response). vHIT results were as follows: 10 patients (32\%) had abnormal test results (Figure 4). Lateral canal was affected in 9 patients (29\%), anterior canal in 9 patients (29\%) and posterior canal in 5 patients (16\%).
Nine patients (29\%) had multi-canal affection. One patient (3\%) had lateral canal affection with prolonged latency of CVEMP. Out of the seventeen patients (55\%) who complained of dizziness, 14 had abnormal vestibular test results, And out of 14 patient who did not complain of dizziness, 10 patients had abnormal vestibular test results, Thus, there was no statistically significant association between complaint of dizziness and presence or absence of vestibular insult $(p=0.62)$ (Table 3$)$.

\begin{tabular}{|c|c|c|c|c|}
\hline \multirow[b]{2}{*}{ Variable } & \multicolumn{2}{|c|}{ Dizziness } & \multirow[b]{2}{*}{ Test value } & \multirow[b]{2}{*}{$\mathrm{p}$-value } \\
\hline & $\begin{array}{c}\text { Present }(n=17) \\
N(\%)\end{array}$ & $\begin{array}{c}\text { Absent }(n=14) \\
N(\%)\end{array}$ & & \\
\hline \multicolumn{5}{|l|}{ Vestibular insult } \\
\hline - $\quad$ Present & $14(58)$ & $10(57)$ & \multirow{2}{*}{0.24} & \multirow{2}{*}{$0.62^{a}$} \\
\hline - Absent & $3(42)$ & $4(43)$ & & \\
\hline
\end{tabular}

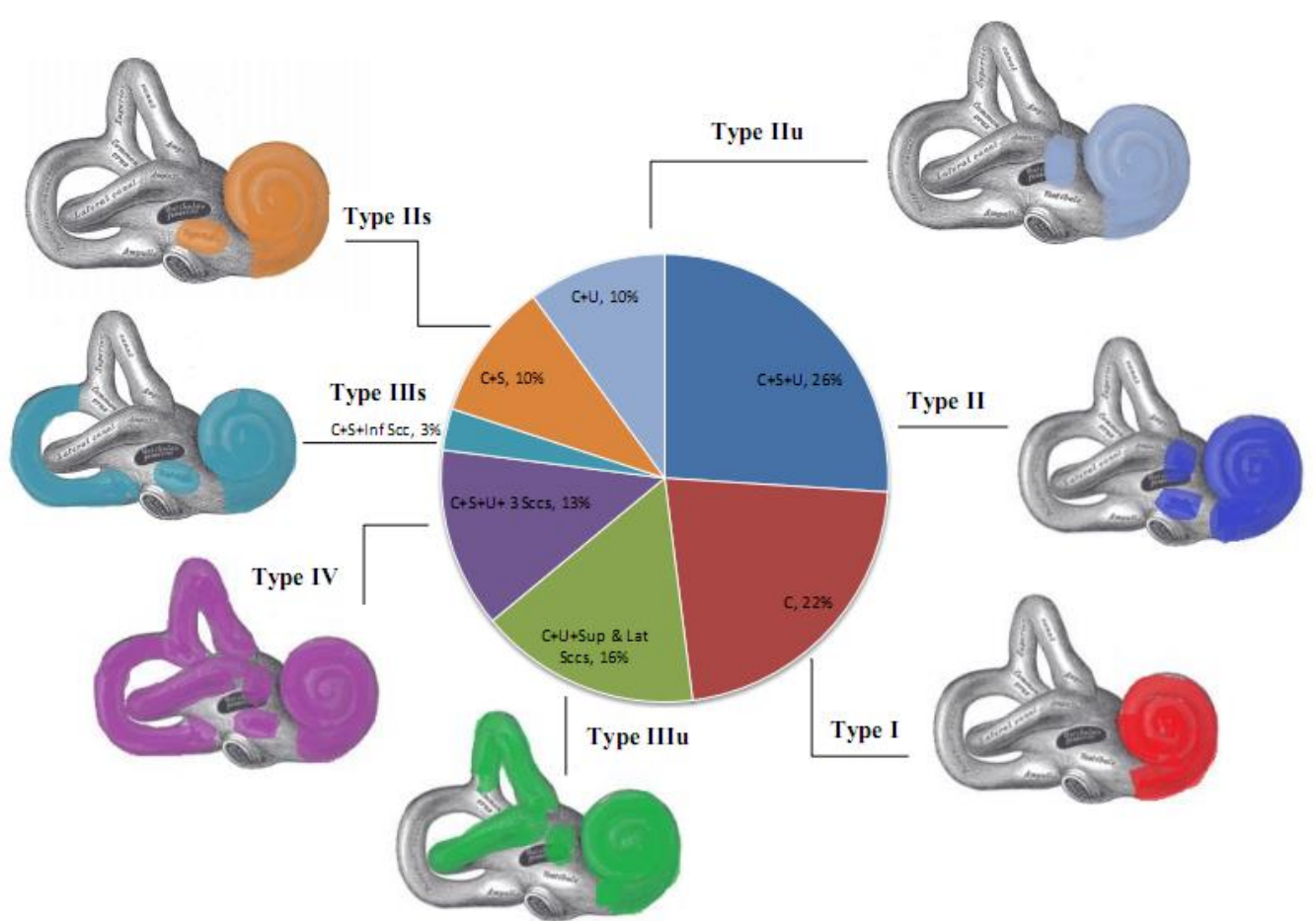

Figure 1: Schematic presentation of different vestibular insult patterns accompanying SSNHL ( $C=$ Cochlea, $\mathrm{S}=$ Saccule, $\mathrm{U}=$ Utricle, $\mathrm{SCC}=$ Semicircular canal)

By combining the results of CVEMP, oVEMP and VHIT, 4 types of vestibular insults be identified in the study group: Type I: normal vestibular function- only cochlea was affected, Type II: otolithic organs insult in addition to the cochlear insult, Type III: 
semicircular canal insult in addition to the cochlear insult. Type IV: total labyrinthine insult, cochlea, otolith organs and semicircular canals, all were affected. These types were found in the study group as follows: Type I in 7 patients (22\%), Type II in 14 patients (45\%), Type III in 6 patients (19\%) and Type IV in 4 patients (13\%).

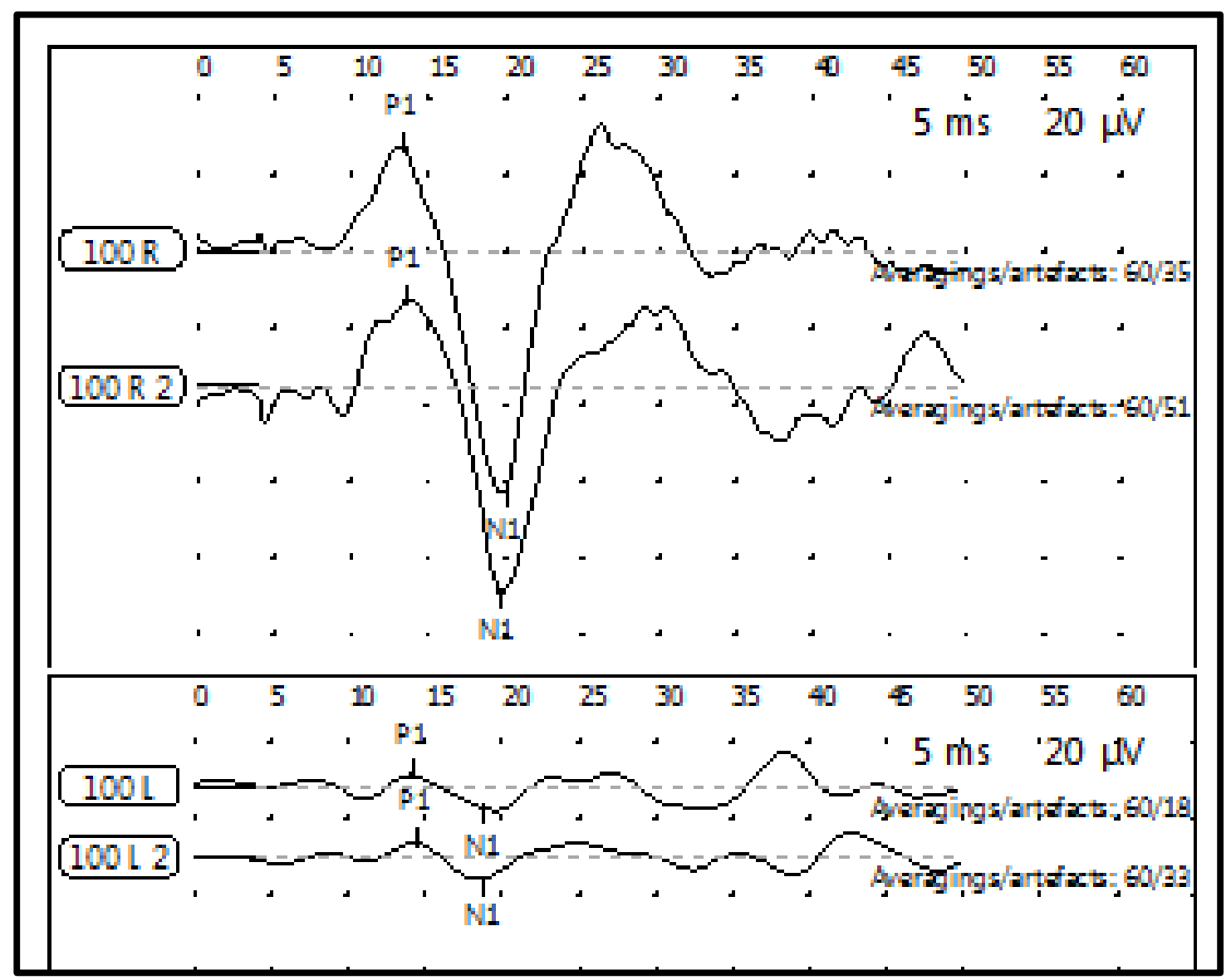

Figure 2: Bilateral cVEMP results showing asymmetrical amplitude (IAD 64\%), markedly affected on the left side

\section{Discussion}

In this study, we utilized the VEMP and VHIT to characterize the vestibular insult in patients with SSNHL and to classify it into distinguishable patterns. In these patients vestibular system is exposed to damage by the same insult as cochlea. Several studies reported the existence of such damage $\mathrm{e}^{(12-14)}$. Basal turn of the cochlea is generally more vulnerable to damage than the apical turn. In our study, the most frequent audiometric configuration was the high-frequency loss, followed by the flat configuration, the lowtone, and at last total hearing loss. The higher incidence of high-frequency audiometric configuration among SSNHL patients has been studied by many authors ${ }^{(13-15)}$. Higher vulnerability of basal cochlea to damage than the apical part was attributed to the basal OHCs having significantly lower level of the antioxidant glutathione compared with apical OHCs. This exposes to more free-radical damage than apical ones ${ }^{(14)}$. Increased risk for intracellular calcium overload also make them more 
susceptible to damage and apoptosis(15,16). found reduced amplitudes to be the Several studies used VEMP to evaluate the dominant abnormality in VEMPs of SSNHL effect of SSNHL upon otolithic organs ${ }^{(16-18)}$. patient rather than delayed latencies. D In our study, the most noticed abnormality Basta and his colleagues attributed this to of CVEMP and oVEMP was reduced the diminished vestibular hair cells or amplitude. Huiqian Yu and Huawei $\mathrm{Li}^{(17)}$ also Scarpa's ganglion cells ${ }^{(18)}$.

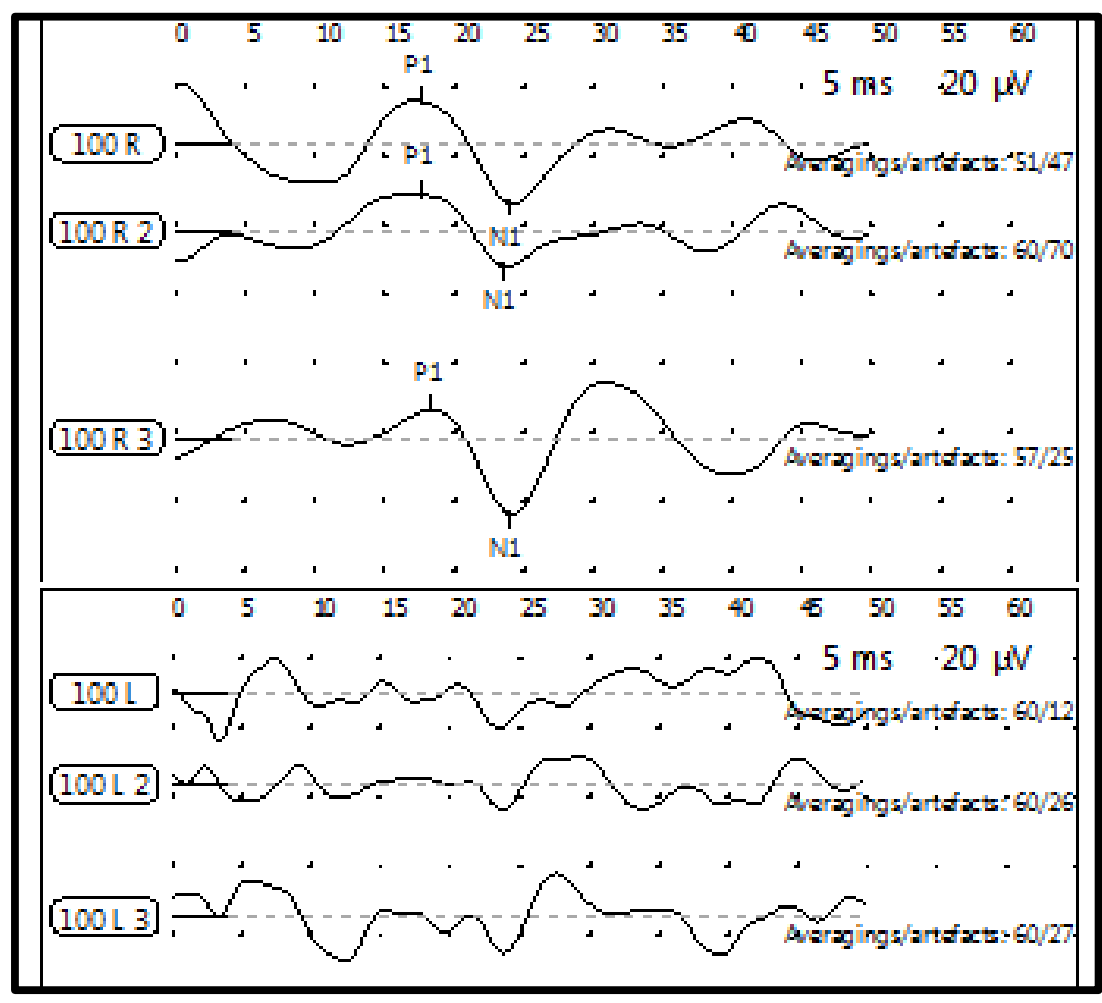

Figure 3: Bilateral cVEMP showing totally absent waves in Left ear

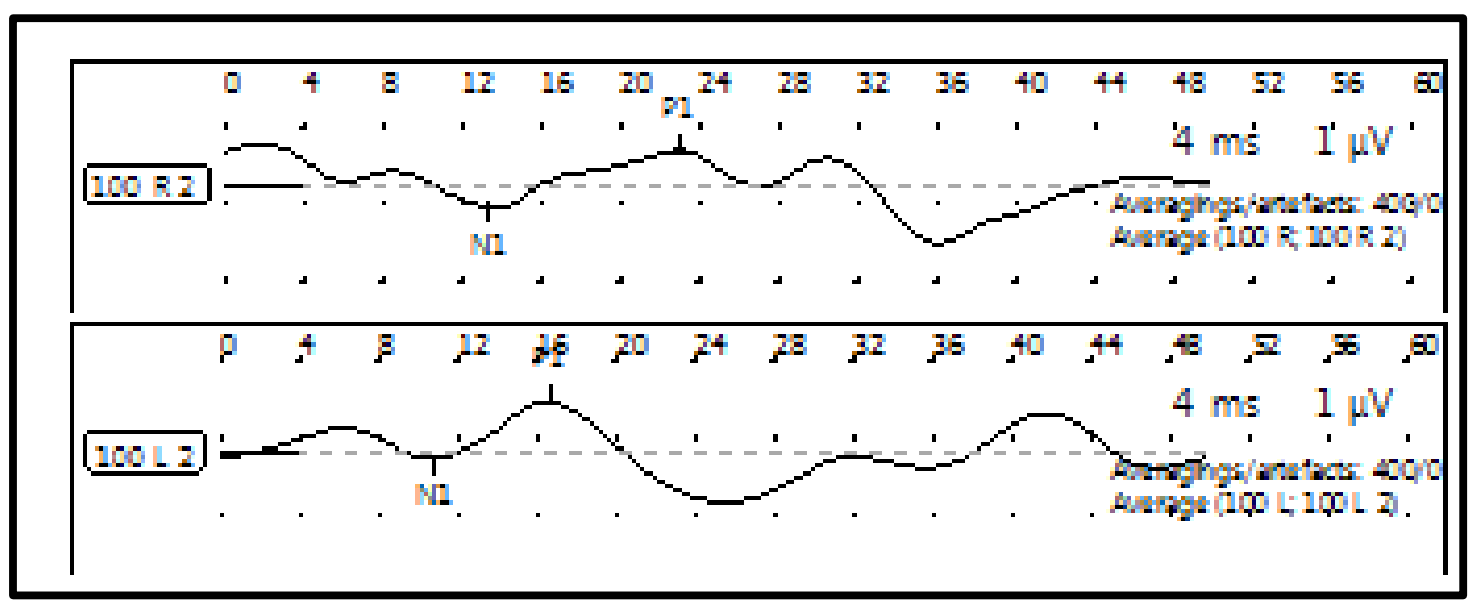

Figure 4: Bilateral oVEMP showing delayed waves latencies in Right ear (>12.1 msec)

On the other hand, Abnormal VEMP waves' latencies were reportedly common in pathologies involving central vestibular system as multiple sclerosis or vestibular schwannoma due to delayed neural transmission caused by destruction of the 
neural sheath ${ }^{(19-22)}$. In our study, we found 20 patients (65\%) with abnormal oVEMP test results vs. 16 patients (52\%) with abnormal CVEMP test results. This indicates increased susceptibility of utricular macula compared to saccular one. KH Lim(20) studied 144 SSNHL patients with VEMP and caloric irrigation. His oVEMP/cVEMP ratio was more than one in most of the patients and this is consistent with our results. Utricular macula is supplied by the anterior vestibular artery while the saccular macula receives dual blood supply from both the anterior and posterior vestibular arteries ${ }^{(21)}$.

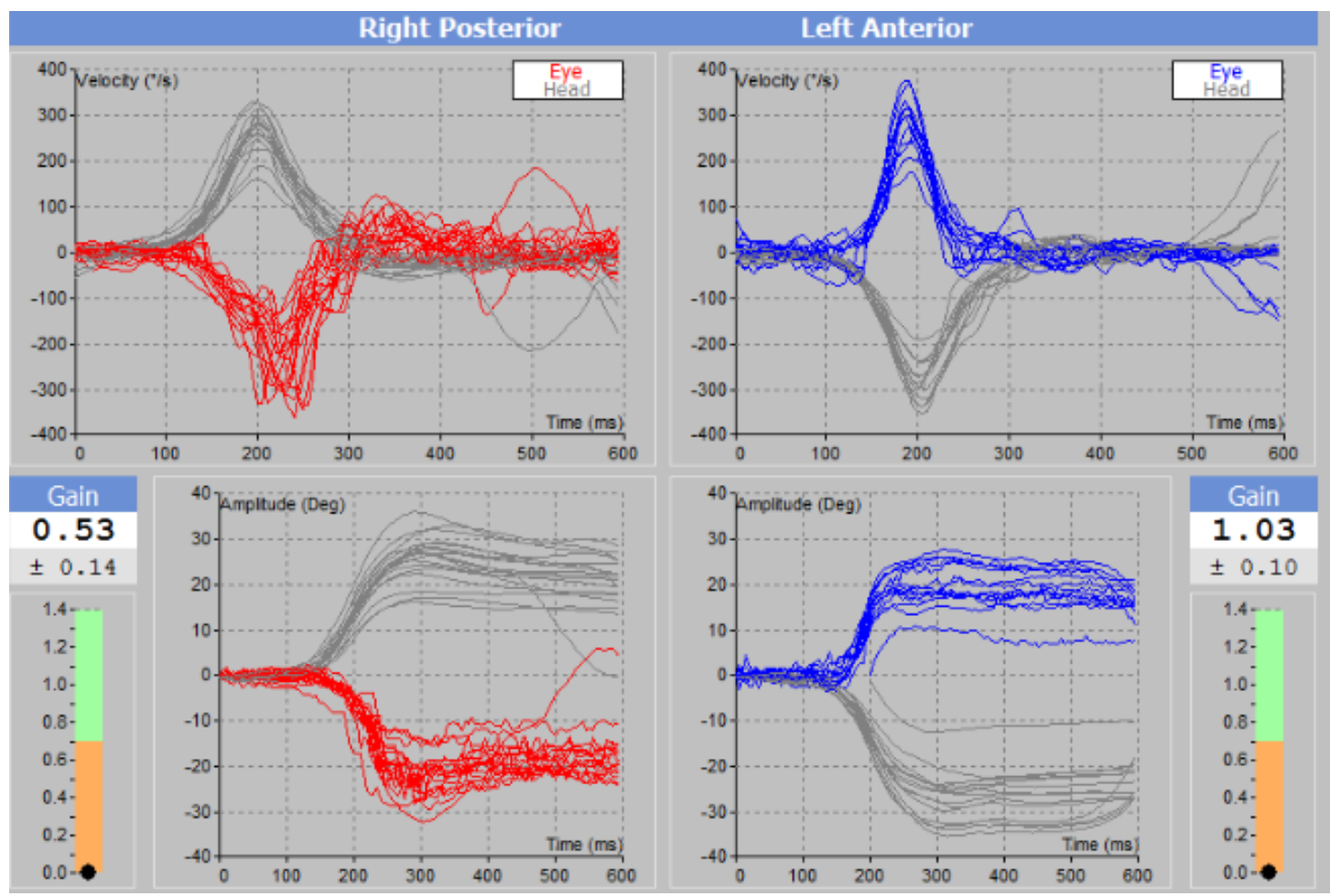

Figure 5: Right anterior canal reduced gain and multiple covert catch-up saccades

Superior vestibular nerve which innervates the utricular macule and its arteriole pass through a relatively narrow and long passage rendering the nerve and its arteirole more vulnerable to entrapment and ischemic changes(22,23). Video HIT was utilized to denote the integrity of each semicircular canal individually. In our study, 9 patients (29\%) had multi-canal affection with the anterior and lateral canals affected in 29\% of patients while posterior canal was affected in $16 \%$ of patients. Using patients with SSHNL has been reported by Q Yao and his colleagues ${ }^{(23)}$. Using vHIT in 22 patients with SSNHL Q Yao and his colleagues found that $33 \%$ of patients had anterior and lateral canal affection while PC was affected in only $9 \%$. By combining the previous test results, four different patterns of vestibular insult could be identified as following: Type 0 (normal vestibular testing) was found in only $7 \%$ of our patients. Patients with SSNHL have great chance to have some degree of vestibular insult than not. The anatomical proximity and the physiological sharing of endolymph between the cochlea and the vestibular apparatus make this a real possibility. Type I (cochlear \& otolithic): was found in $45 \%$ of patients; only $50 \%$ of them complained of dizziness. This means that saccular and utricular hair cells are more liable to damage than the hair cells located in the ampulla of SCCS. JP Vasama in his study of 12 temporal bone specimens of patients with SSNHL, found less number of residual hair cells and more atrophy of otolithic 
membranes than in $\mathrm{SSCs}^{(24)}$. Moreover, SN Merchant reported increased density of hair cells and supporting cell ratio in the cristae ampullaris compared to the maculae ${ }^{(25)}$. He found the mean density of hair cells is 80 per $0.01 \mathrm{~mm}^{2}$ in the cristae, 68 cells per $0.01 \mathrm{~mm}^{2}$ in the utricle, and 61 cells per $0.01 \mathrm{~mm}^{2}$ in the saccule, and the ratio of supporting cells to hair cells to be 2.4:1 in the cristae and 1.3:1 in the maculae. Hair cells in cristae were found to have narrower gap junctions and abundance of potassium transporters making them less liable to injury ${ }^{(26)}$. Type II (cochlear, otolithic \& SSCs): was found in 6 patients (19\%) in our study. Involvement of the cochlea and the neighboring otolithic organs within the labyrinth points to a diffuse pathology affecting these endolymphatically-connected organs. This connection may allow transmission of biochemical changes between the damaged cochlea, and the nearby saccule and utricle. Depending on which otolithic organ is affected we had 2 subypes: IIs(cochlea, saccule \& SSCS) in 5 patients (16\%) and Ilu (cochlea, utricle \& SCCs) in only one patient (3\%); again reflecting the increased susceptibility of superior vestibular territory to injury more than the inferior one ${ }^{(27-29)}$. Type III (total labyrinthine insult) was found in 4 patients in our study (13\%) This pattern may result from a complete labyrinthine artery occlusion or viral labyrinthitis. Total vestibular loss along with SSNHL has been reported to be a warning sign for major vasoocclussive diseases ${ }^{(28)}$. In their cohort study, Lin $\mathrm{Hc}$ et al reported increased stroke risk in patients with total SSNHLand vestibular loss than controls in 5-years follow-up period(29). In our study, three patients presenting with this type (75\%) were on dialysis. SSNHL was either during the dialysis session or just few hours after it. Osmotic disequilibrium or microemboli from degraded cellulose acetate hemodialysis membrane may explain this type of vascular accident(30). Finally, we didn't find isolated single SCC lesion along with cochlear lesion. In other studies made to identify involvement of SCCs in course of SSNHL ${ }^{(31,32)}$, no isolated SCC insult was detected. This is in accordance with our findings

\section{Study Limitations}

Limitations of our study included small sample size due to rarity of SSNHL, moreover, exclusion criteria restrictions to ensure proper mapping of vestibular insult. Other limitation was lacking of searching for definitive etiology due to large time and resources consumption. Larger data collection is essential for further research regarding the vestibular insult types associated with SSNHL and their possible relevance to prognosis, testing newer drugs or treatment modality.

\section{Conclusion}

We conclude that vestibular insult in SSNHL in our study was categorized into four types. Seventy eighty percent had otolithic organ affection (Type I, II and III) while SCC insult was present in only $32 \%$ of patients (Type II and III) and the presence and absence of vestibular insult was not associated with complaint of dizziness. We recommend that patients with SSNHL particularly type II and III should be screened for vascular risk factors. Also, they should undergo vestibular testing to determine the need for vestibular rehabilitation.

Conflicts of interests: None to be declared

Financial and material support: None

\section{References}

1. Kuhn M, Heman-Ackah SE, Shaikh JA, Roehm PC. Sudden sensorineural hearing loss: a review of diagnosis, treatment, and prognosis. Trends in amplification. 2011 Sep;15(3):91-105.

2. Schreiber BE, Agrup C, Haskard DO, Luxon LM. Sudden sensorineural 
hearing loss. The Lancet. $2010 \mathrm{Apr}$ 9;375(9721):1203-11.

3. Agrawal Y, Carey JP, Della Santina CC, Schubert MC, Minor LB. Disorders of balance and vestibular function in US adults: data from the National Health and Nutrition Examination Survey, 2001-2004. Arch. Intern. Med. 2009 May 25;169(10):938-44.

4. Khan FK, Balraj A, Lepcha A. Vestibular evoked myogenic potential in sudden sensorineural hearing loss. Indian J Otol. 2013 Apr 1;19(2):55.

5. Mira E. Improving the quality of life in patients with vestibular disorders: the role of medical treatments and physical rehabilitation. Int. J. Clin. Pract. 2008 Jan 1;62(1):109-14.

6. Fujimoto $C$, Egami $N$, Kinoshita $M$, Sugasawa K, Yamasoba T, Iwasaki S. Involvement of vestibular organs in idiopathic sudden hearing loss with vertigo: an analysis using oVEMP and CVEMP testing. Clinical Neurophysiology. 2015 May 31;126(5):1033-8.

7. Janfaza P, editor. Surgical anatomy of the head and neck. Harvard University Press; 2011 Jun 15, page 932

8. Weiss D, Böcker AJ, Koopmann $M$, Savvas E, Borowski M, Rudack C. Predictors of hearing recovery in patients with severe sudden sensorineural hearing loss. WJOHNS. 2017 Apr 4;46(1):27.

9. Curthoys IS, MacDougall HG, McGarvie LA, Weber KP, Szmulewicz D, Manzari L, Burgess AM, Halmagyi GM. The video head impulse test (VHIT). Balance Function Assessment and Management. San Diego, CA: Plural Publishing. 2014 Dec 31:391-430.

10. MacDougall HG, McGarvie LA, Halmagyi GM, Curthoys IS, Weber KP. Application of the video head impulse test to detect vertical semicircular canal dysfunction. Otology \& Neurotology. 2013 Aug 1;34(6):974-9.

11. Weber KP, Aw ST, Todd MJ, McGarvie LA, Curthoys IS, Halmagyi GM. Head impulse test in unilateral vestibular loss Vestibulo-ocular reflex and catch-up saccades. Neurology. 2008 Feb 5;70(6):454-63.

12. Park, Seung-Wan Jung, Chung-Ku Rhee $H M$. Vestibular diagnosis as prognostic indicator in sudden hearing loss with vertigo. Acta Oto-Laryngologica. 2001 Jan 1;121(533):80-3.

13. Mattox DE, Simmons FB. Natural history of sudden sensorineural hearing loss. Ann. Otol. Rhino. 1977 Jul;86(4):463-80.

14. Rybak LP, Whitworth CA. Ototoxicity: therapeutic opportunities. Drug discovery today. 2005 Oct 1;10(19):131321.

15. Furuta H, Luo L, Hepler K, Ryan AF. Evidence for differential regulation of calcium by outer versus inner hair cells: plasma membrane Ca-ATPase gene expression. Hearing research. 1998 Sep 1;123(1-2):10-26.

16. Oiticica J, Bittar RS, Castro CC, Grasel S, Pereira LV, Bastos SL, Ramos AC, Beck R. Contribution of audiovestibular tests to the topographic diagnosis of sudden deafness. Int. Arch. Otorhinolaryngol. 2013 Sep;17(3):30514.

17. $\mathrm{Yu} \mathrm{H}$, Li H. Vestibular dysfunctions in sudden sensorineural hearing loss: a systematic review and meta-analysis. Front Neurol. 2018 Feb 5;9:45.

18. Merchant SN, Velazquez-Villasenor L, Tsuji K, Glynn RJ, Wall 3rd C, Rauch SD. Temporal bone studies of the human peripheral vestibular system. Normative vestibular hair cell data. Ann Otol Rhinol Laryngol Suppl 2000; 181:3-13.

19. Krempaska S, Koval J. The role of vestibular evoked myogenic potentials (VEMPs) in vestibulopathy diagnostics. Bratisl Lek Listy. 2012 Jan 1;113(5):301-6.

20. Lim KH, Jeong YJ, Han MS, Rah YC, Cha J, Choi J. Comparisons among Vestibular Examinations and Symptoms of Vertigo in Sudden Sensorineural Hearing Loss Patients. bioRxiv. 2018 Jan 1:479352. 
21. Schuknecht HF, Kitamura K. Vestibular neuritis. Ann Otol Rhinol Laryngol. 1981 Jan;90(1-suppl):1-9.

22. Goebel JA, O'mara W, Gianoli G. Anatomic considerations in vestibular neuritis. Otol. Neurotol. $2001 \mathrm{Jul}$ 1;22(4):512-8.

23. Yao Q, Xu C, Wang H, Shi H, Yu D. Video head impulse test results suggest that different pathomechanisms underlie sudden sensorineural hearing loss with vertigo and vestibular neuritis: Our experience in fifty-two patients. Clin Otolaryngol. 2018 Dec;43(6):1621-4.

24. Vasama JP, Linthicum Jr FH. Idiopathic sudden sensorineural hearing loss: temporal bone histopathologic study. Ann Otol Rhinol Laryngol. 2000 Jun;109(6):527-32.

25. Merchant SN, Tsuji K, Wall III C, Velázquez-Villaseñor L, Glynn RJ, Rauch SD. Temporal bone studies of the human peripheral vestibular system: 1. Normative vestibular hair cell data. Ann Otol Rhinol Laryngol. 2000 May;109(5_suppl):3-13.

26. Lopez I, Honrubia V, Lee SC, Schoeman G, Beykirch K. Quantification of the process of hair cell loss and recovery in the chinchilla crista ampullaris after gentamicin treatment. Int. J. Dev. Neurosci. 1997 Jul 1;15(4-5):447-61.

27. Goebel JA, O'mara W, Gianoli G. Anatomic considerations in vestibular neuritis. Otol. Neurotol. $2001 \mathrm{Jul}$ 1;22(4):512-8.

28. Lee H, Baloh RW. Sudden deafness in vertebrobasilar ischemia: clinical features, vascular topographical patterns and long-term outcome. J. Neurol. Sci. 2005 Jan 15;228(1):99-104.

29. Lin HC, Chao PZ, Lee HC. Sudden sensorineural hearing loss increases the risk of stroke: a 5-year follow-up study. Stroke. 2008 Oct 1;39(10):27448.

30. Lasisi OA, Salako BL, Kadiri S, Arije A, Oko-Jaja R, Ipadeola A, Olatoke F. Sudden sensorineural hearing loss and hemodialysis. Ear Nose Throat J. 2006 Dec 1;85(12).

31. Rambold HA. Testing of the Semicircular Canal Function in Vertigo and Dizziness. Up to Date on Meniere's Disease. 2017 Oct 4:119. 
Editor: use the journal abbreviation although the references. i.e. Arc Inten

1

4

5

6 Fujimoto C, Egami N, Kinoshita M, Sugasawa K, Yamasoba T, Iwasaki S. Involvement of vestibular organs in idiopathic sudden hearing loss with vertigo: an analysis using oVEMP and cVEMP testing. Clinical Neurophysiology. 2015 May 31;126(5):1033-8.

7 Janfaza P, editor. Surgical anatomy of the head and neck. Harvard University Press; 2011 Jun 15, page 932

8 Weiss D, Böcker AJ, Koopmann M, Savvas E, Borowski M, Rudack C. Predictors of hearing recovery in patients with severe sudden sensorineural hearing loss. WJOHNS. 2017 Apr 4;46(1):27. 
9 Curthoys IS, MacDougall HG, McGarvie LA, Weber KP, Szmulewicz D, Manzari L, Burgess AM, Halmagyi GM. The video head impulse test (vHIT). Balance Function Assessment and Management. San Diego, CA: Plural Publishing. 2014 Dec 31:391-430.

11 Weber KP, Aw ST, Todd MJ, McGarvie LA, Curthoys IS, Halmagyi GM. Head impulse test in unilateral vestibular loss Vestibulo-ocular reflex and catch-up saccades. Neurology. 2008 Feb 5;70(6):454-63.

12 Park, Seung-Wan Jung, Chung-Ku Rhee HM. Vestibular diagnosis as prognostic indicator in sudden hearing loss with vertigo. Acta Oto-Laryngologica. 2001 Jan 1;121(533):80-3.

13 Mattox DE, Simmons FB. Natural history of sudden sensorineural hearing loss. Ann. Otol. Rhino. 1977 Jul;86(4):463-80.

14 Rybak LP, Whitworth CA. Ototoxicity: therapeutic opportunities. Drug discovery today. 2005 Oct 1;10(19):1313-21.

15 Furuta H, Luo L, Hepler K, Ryan AF. Evidence for differential regulation of calcium by outer versus inner hair cells: plasma membrane Ca-ATPase gene expression. Hearing research. 1998 Sep 1;123(1-2):10-26. 
16 Oiticica J, Bittar RS, Castro CC, Grasel S, Pereira LV, Bastos SL, Ramos AC, Beck R. Contribution of audiovestibular tests to the topographic diagnosis of sudden deafness. Int. Arch. Otorhinolaryngol.. 2013 Sep;17(3):305-14.

$17 \mathrm{Yu} \mathrm{H,} \mathrm{Li} \mathrm{H.} \mathrm{Vestibular} \mathrm{dysfunctions} \mathrm{in} \mathrm{sudden} \mathrm{sensorineural} \mathrm{hearing} \mathrm{loss:} \mathrm{a} \mathrm{systematic}$ review and meta-analysis. Front Neurol. 2018 Feb 5;9:45.

18 Merchant SN, Velazquez-Villasenor L, Tsuji K, Glynn RJ, Wall 3rd C, Rauch SD. Temporal bone studies of the human peripheral vestibular system. Normative vestibular hair cell data. Ann Otol Rhinol Laryngol Suppl 2000;181:3-13.

19 Krempaska S, Koval J. The role of vestibular evoked myogenic potentials (VEMPs) in vestibulopathy diagnostics. Bratisl Lek Listy. 2012 Jan 1;113(5):301-6.

20 Lim KH, Jeong YJ, Han MS, Rah YC, Cha J, Choi J. Comparisons among Vestibular Examinations and Symptoms of Vertigo in Sudden Sensorineural Hearing Loss Patients. bioRxiv. 2018 Jan 1:479352.

21 Schuknecht HF, Kitamura K. Vestibular neuritis. Ann Otol Rhinol Laryngol. 1981 Jan;90(1_suppl):1-9.

22 Goebel JA, O'mara W, Gianoli G. Anatomic considerations in vestibular neuritis. Otol. Neurotol. 2001 Jul 1;22(4):512-8. 
23 Yao Q, Xu C, Wang H, Shi H, Yu D. Video head impulse test results suggest that different pathomechanisms underlie sudden sensorineural hearing loss with vertigo and vestibular neuritis: Our experience in fifty two patients. Clin Otolaryngol. 2018 Dec;43(6):1621-4. 